\title{
Selected factors affecting adherence in the pharmacological treatment of arterial hypertension
}

\author{
This article was published in the following Dove Press journal: \\ Patient Preference and Adherence \\ I March 2017 \\ Number of times this article has been viewed
}

\author{
Beata Jankowska-Polańska' \\ Anna Chudiak' \\ Izabella Uchmanowicz' \\ Krzysztof Dudek ${ }^{2}$ \\ Grzegorz Mazur 3 \\ 'Department of Clinical Nursing, \\ Wroclaw Medical University, \\ ${ }^{2}$ Department of Logistics and \\ Transport Systems, Faculty of \\ Mechanical Engineering, Wrocław \\ University of Technology, \\ ${ }^{3}$ Department and Clinic of Internal \\ and Occupational Diseases and \\ Hypertension, Wroclaw Medical \\ University, Wroclaw, Poland
}

Background: Low adherence to hypertension (HT) management is one of the major contributors to poor blood pressure (BP) control. Approximately $40 \%-60 \%$ of patients with HT do not follow the prescribed treatment. The aim of the study was to analyze the relationship between selected variables and adherence to hypotensive pharmacological treatment. Besides socioclinical variables, the study focused on the role of illness acceptance.

Participants and methods: The study included 602 patients with HT. Adherence and acceptance of illness were assessed using the following validated instruments: the Acceptance of Illness Scale (AIS) and the Morisky Medication Adherence Scale (MMAS).

Results: The high-adherence group comprised a significantly higher percentage of patients with high illness acceptance scale scores than that of patients with low-to-moderate scores ( 42.4 vs $31.8 \% ; P=0.008<0.01$ ). The odds ratio $(\mathrm{OR})$ showed that high adherence to pharmacological treatment was $>1.5$ times as likely to occur in the high acceptance group as in the low-to-moderate acceptance group ( $\mathrm{OR}=1.58,95 \%$ CI 1.14-2.19). Spearman's rank correlation coefficients showed statistically significant correlations between adherence and sex (men $\rho=-0.101 ; P=0.012)$, age $>45-66$ years $(\rho=0.098 ; P=0.015)$, higher education level $(\rho=0.132$; $P=0.001)$, grade ESC of HT ( $\rho=-0.037 ; P=0.057)$, receiving one-tablet polytherapy $(\rho=0.131$; $P=0.015)$, and illness acceptance $(\rho=0.090 ; P=0.024)$.

Conclusion: Acceptance of illness is correlated with adherence to pharmacological treatment, and consideration should be given to more widespread assessment of illness acceptance in daily practice. Male sex, age $>45-66$ years, duration of illness grade ESC of HT, and receiving one-tablet polytherapy are significant determinants of adherence to pharmacological treatment in HT.

Keywords: adherence, hypertensive treatment, illness acceptance

\section{Background}

Despite significant advances in our ability to treat high BP over the last few decades, HT continues to be a major public health problem.

A total of $44 \%$ of strokes and $47 \%$ of cardiac deaths are attributed to suboptimal BP control. Despite the variety of antihypertensive medications available, including combination drugs, HT often remains uncontrolled. ${ }^{2}$ The rate of nonadherence reported in various studies ranges from 10 to $92 \% .^{3}$ In developed countries, it is estimated at 50\%. ${ }^{4}$ Adherence is typically better in patients with acute disease and becomes worse in chronically ill patients. ${ }^{5,6}$ The available studies show that $50 \%$ of hypertensive patients discontinue treatment within 12 months of its beginning. Another $30 \%$ continue treatment but do not comply fully with the prescribed protocol. ${ }^{7}$ Low adherence to HT management is one of the major contributors to poor BP control. ${ }^{8,9}$
Correspondence: Beata Jankowska-

Polańska

Department of Clinical Nursing, Wroclaw

Medical University, ul. Bartla 3, 8I-6I8

Wrocław, Poland

Email bianko@poczta.onet.pl 
Therefore, it is useful to measure patients' adherence behaviors to provide evidence regarding BP control. Understanding the barriers affecting a patient's ability to adhere to antihypertensive therapy will allow researchers to design effective interventions. Moreover, a better understanding will help evaluate the impact of these interventions on perceived and actual barriers to medication use, adherence rates, and ultimately, patient outcomes. ${ }^{10}$

The WHO (2003) $)^{11}$ identified three groups of factors associated with poor adherence. The first group is associated with the complexity of the disease and its treatment and includes the presence of comorbidities, complications, long disease duration, and the number and frequency of use of prescribed medications. The second group includes intrapersonal factors such as sex, age, self-efficacy, alcohol abuse, and depression. The third group comprises interpersonal factors that include patient-provider communication and social support. ${ }^{12}$ In the literature, the most commonly discussed barriers include depression, lack of social support, geriatric syndrome, and poor quality of life..$^{8,9}$ Other significant factors include age, sex, education, race, geographical region of residence, and illness perceptions. ${ }^{13-15}$ Participation in the treatment process is affected positively by knowledge about the illness and acceptance of illness. Some articles have been published on associations between illness acceptance and treatment adherence. ${ }^{16}$

Acceptance of illness is a complex process that plays a key role in adapting to chronic illness and may be affected by clinical factors, illness symptoms, treatment quality, medication side effects, individual predispositions resulting from imposed limitations, and strategies for coping with the illness. ${ }^{17}$ Illness acceptance engenders a sense of security and mitigates the negative reactions related to the illness and treatment. Better acceptance of illness corresponds not only to a lower intensity of negative emotions and reactions but also to a greater involvement of the patient in the treatment process and to better self-control capabilities. ${ }^{18}$ Higher levels of self-care result in better adherence to pharmacological treatment and better BP control. . $^{19,20}$

A previous study on adherence confirmed the correlation between acceptance of illness and adherence to HT treatment but mainly with regard to nonpharmacological measures. Patients' sex and education and the illness duration correlated with adherence to pharmacological and nonpharmacological treatments in HT. ${ }^{18}$

The aim of this study was to analyze the relationship between selected variables and adherence to pharmacological treatment in patients with HT. The study focused on the role of selected sociodemographic and clinical determinants, including illness acceptance, in HT treatment and on identifying those factors that could be correlated with adherence. The variables studied were as follows: patients' sex, age, marital status, professional activity, duration of illness, HT grade, and the number of drugs prescribed (monotherapy, polytherapy, or polytherapy in one tablet).

\section{Participants and methods Participants}

The study used structured interviews with 707 adult outpatients attending a general practitioners' clinic in Wrocław between February 2014 and April 2015. The inclusion criteria were as follows: age $>18$ years, HT diagnosis in line with the guidelines of the $\mathrm{ESH},{ }^{21}$ treatment with at least one hypotensive agent for the past year, and informed consent. Patients diagnosed with other serious diseases (cardiac insufficiency, renal insufficiency, and neoplasms) and severe cardiovascular complications or other severe concomitant diseases, which could affect illness acceptance and adherence to therapeutic guidelines, were excluded from the study due to their complex treatment schemes and the possibility of adverse effects and reactions occurring as a result of being treated with multiple medications. Of the 707 subjects who met the criteria, 87 subjects refused to take part in the study without giving a reason.

Patients were selected by a panel consisting of a physician and a nurse - specialist in the field of cardiac nursing. All patients received information about the purpose and nature of the study and provided written informed consent to participate. The questions concerned the last 6 months of therapy and were answered directly by the patients. For each patient, at least two BP measurements and a comprehensive physical examination were performed, and patient histories were taken. Whenever systolic and diastolic BP values fell into different categories, the patient was classified into the higher category.

All patients were informed of the purpose and nature of our study and provided their written informed consent to be included in it. All patients completed all questionnaires.

Information concerning the sociodemographic and clinical data come from the outpatients' clinic files.

The sample group was homogeneous and suitable for statistical analysis.

\section{Ethical consideration}

The study was approved by the Independent Bioethics Committee of the Wroclaw Medical University (approval no KB 136/2015). All participants gave written informed consent after thorough explanation of the procedures involved. The study was carried out in accordance with the tenets of the Declaration of Helsinki. 


\section{Measures}

The sociodemographic and clinical characteristics recorded included participant's age, sex, marital status, education, professional activity, duration of HT, and the number of prescription medications taken daily.

\section{Instruments}

The following two validated instruments were used: the AIS and the MMAS- 8 . The scales were distributed by a cardiac nurse in the waiting room of the clinic, but the patients answered the questions themselves.

The AIS was developed by Felton, Revenson, and Hinrichsen and adapted into Polish by Juczyński. The scale evaluates the extent of adaptation to changes resulting from the illness. It comprises eight statements regarding difficulties and limitations imposed by the illness, including the loss of independence, the sense of being dependent on others, and decreased self-esteem. Answers are provided using a 5-item Likert scale, with 1 meaning "strongly agree" and 5 meaning "strongly disagree". The total score, between 8 and 40 points, indicates the acceptance of the illness level, with higher scores denoting more acceptance. The reliability and internal consistency of the Polish version of AIS (Cronbach's alpha 0.82) are similar to those of the original instrument. Participants were categorized as having low or high self-reported acceptance of illness based on their mean AIS score in three consecutive surveys. ${ }^{22}$

Self-reported medication adherence was assessed using the MMAS- 8 . The self-reported MMAS- 8 tool is simple to administer, reliable, and economical in clinical practice. The MMSA- 8 was designed to facilitate the identification of barriers to and behaviors associated with adherence to chronic medication. The tool has been determined to be reliable and significantly associated with BP control in individuals with HT as well as with antihypertensive medication pharmacy fill rates. Scores on the MMAS- 8 range from 0 to 8 , with scores $<6$ reflecting low adherence, $6-<8$ reflecting moderate adherence, and 8 reflecting high adherence. ${ }^{23}$ In this study, the following two dichotomous factors were considered: low-to-moderate adherence ( $<8$ points in the MMAS- 8 ) and high adherence ( 8 points in the MMAS- 8 ).

\section{Statistical analysis}

Correlations between adherence (MMAS-8 scores) and illness acceptance (AIS scores) were analyzed using Spearman's rank correlation coefficients $(\rho)$ and significance levels $(P)$. Because the data included many dependent observations, gamma values were also calculated. The independence of the cross-tabulated qualitative and ordinal characteristics was verified using Pearson's chi-squared test. In two-by-two tables, Yates' correction for continuity was used. ${ }^{17}$

Calculations were performed using EXCEL spreadsheets and STATISTICA software (StatSoft Inc., Tulsa, OK, USA).

\section{Results}

\section{Patient characteristics}

In total, 620 patients (including 333 women) aged between 20 and 86 years $(M=58, \mathrm{SD}=14)$ and treated for HT participated in the survey. The duration of illness in the group was between 1 and 38 years $(M=7, \mathrm{SD}=8)$. The patients' basic sociodemographic and clinical characteristics are shown in Table 1.

Adherence to pharmacological treatment was evaluated using the MMAS-8. The mean score was 7 (range: 0.25-8).

Table I Characteristics of the 620 hypertensive patients

\begin{tabular}{|c|c|c|}
\hline Characteristics & $\mathbf{N}$ & $\%$ \\
\hline Female & 333 & 53.7 \\
\hline \multicolumn{3}{|l|}{ Age (years) } \\
\hline $20-45$ & 133 & 21.5 \\
\hline $46-65$ & 307 & 49.5 \\
\hline$\geq 66$ & 180 & 29.0 \\
\hline \multicolumn{3}{|l|}{ Duration of the illness (years) } \\
\hline $1-5$ & 231 & 37.2 \\
\hline $5.1-10$ & 192 & 31.0 \\
\hline$>10$ & 197 & 31.8 \\
\hline Living alone & 197 & 31.0 \\
\hline \multicolumn{3}{|l|}{ Education } \\
\hline None or primary & 187 & 30.2 \\
\hline High school & 273 & 44.0 \\
\hline College/university & 160 & 25.8 \\
\hline Professionally active & 286 & 46.1 \\
\hline \multicolumn{3}{|l|}{ BMI $\left(\mathrm{kg} / \mathrm{m}^{2}\right)$} \\
\hline$<20.0$ & 161 & 26.0 \\
\hline $20-25$ & 245 & 39.5 \\
\hline$>25$ & 214 & 34.5 \\
\hline \multicolumn{3}{|c|}{ ESC hypertension grade (mean value of the two measurements) } \\
\hline I20-129 and/or 80-84 & 15 & 2.4 \\
\hline 130-139 and/or 85-89 & 186 & 30.0 \\
\hline I40-159 and/or 90-99 & 287 & 46.3 \\
\hline $160-169$ and/or $100-109$ & 132 & 21.3 \\
\hline \multicolumn{3}{|l|}{ Hypertension treatment } \\
\hline Monotherapy & 128 & 20.6 \\
\hline Polytherapy in one tablet & 91 & 14.7 \\
\hline Polytherapy & 401 & 64.7 \\
\hline \multicolumn{3}{|l|}{ Way of taking medication } \\
\hline Directly from the blister & 450 & 72.6 \\
\hline From daily dispenser box & 27 & 4.4 \\
\hline From weekly dispenser box & 22 & 3.5 \\
\hline Administered by a caregiver & 121 & 19.5 \\
\hline
\end{tabular}

Abbreviations: BMI, body mass index; ESC, European Society of Cardiology. 
The distributions of AIS and MMAS-8 scores differed significantly from normal. Thus, Spearman's regression analysis (Spearman's rank correlation) was used instead of Pearson's regression analysis.

For the whole studied group of 620 patients, a weak positive correlation was found between adherence and acceptance levels. The variable independence test result was near the statistical significance threshold $(P=0.062>0.05)$. With low-to-moderate acceptance patients and low-tomoderate adherence patients grouped together, the correlation between the analyzed factors was statistically significant (Table 2).

To determine the strength of correlations between illness acceptance and medication adherence, Spearman's rank correlation coefficients $(\rho=0.090 ; P=0.024<0.05)$ and gamma values $(\beta=0.133 ; P<0.01)$ were calculated. When adherence and illness acceptance scores were divided into pairs of dichotomous factors, a statistically significant correlation $(P=0.008)$ was found (Table 2).

The high-adherence group comprised a significantly higher percentage of patients with high AIS scores than that of patients with low-to-moderate scores (42.4 vs $31.8 \%$; $P=0.008<0.01)$. The OR shows that high adherence to pharmacological treatment is $>1.5$ times as likely to occur in the high acceptance group as in the low-to-moderate acceptance group (OR $=1.58,95 \%$ CI 1.14-2.19).

The comparative analysis of the adherence level was based on the selected sociodemographic and clinical variables. The impact of the selected sociodemographic factors on the adherence to the recommendations investigated by means of MMAS-8 questionnaire is presented in Table 3 . A statistically significant relationship was observed between adherence to the recommendations of hypertensive treatment and some factors such as sex, age, education, the stage of

Table 2 Numbers (percentages) of patients (out of 620) in the acceptance of illness and adherence subgroups (based on AIS and MMAS-8 scores), chi-squared test results, and OR values with $95 \% \mathrm{Cls}$

\begin{tabular}{|c|c|c|}
\hline \multirow{2}{*}{$\begin{array}{l}\text { Adherence score } \\
\text { (MMAS-8) }\end{array}$} & \multicolumn{2}{|c|}{ Acceptance of illness score, $n(\%)$} \\
\hline & $\begin{array}{l}\text { I. Low to } \\
\text { moderate }(\mathrm{N}=3 \mid 8)\end{array}$ & $\begin{array}{l}\text { 2. High } \\
(\mathrm{N}=302)\end{array}$ \\
\hline I. Low to moderate & $217(68.2)$ & $174(57.6)$ \\
\hline 2. High & $101(31.8)$ & $128(42.4)$ \\
\hline \multicolumn{3}{|c|}{$P=0.008 ; O R=1.58(1.14-2.19)$} \\
\hline
\end{tabular}

Notes: Use of the CMMAS is protected by US and International copyright laws. The permission for use is required. A license agreement is available from Donald $E$ Morisky, MMAS Research (MORISKY) 16636 159th Place SE, Renton, WA 98058 USA, dmorisky@gmail.com.

Abbreviations: AIS, Acceptance of Illness Scale; MMAS-8, 8-item Morisky Medication Adherence Scale; OR, odds ratio.
Table 3 Number (percentage) of 620 hypertensive patients in the subgroups with different levels of adherence (MMAS-8) and selected features of sociodemographic and clinical data and univariate analysis

\begin{tabular}{|c|c|c|c|}
\hline \multirow[t]{2}{*}{ Variables } & \multicolumn{3}{|c|}{ MMAS-8 level (v56), n (\%) } \\
\hline & $\begin{array}{l}\text { Low } \\
(\mathrm{N}=183)\end{array}$ & $\begin{array}{l}\text { Moderate } \\
(\mathrm{N}=208)\end{array}$ & $\begin{array}{l}\text { High } \\
(\mathrm{N}=229)\end{array}$ \\
\hline \multicolumn{4}{|l|}{ Sex } \\
\hline I. Female & $86(47.0)$ & III (53.4) & $136(59.4)$ \\
\hline 2. Male & $97(53.0)$ & $97(46.6)$ & $93(40.6)$ \\
\hline \multicolumn{4}{|c|}{ Pearson chi-square: $P=0.043$, Spearman's $\rho=-0.101 \quad(P=0.012)$} \\
\hline \multicolumn{4}{|l|}{ Age (years) } \\
\hline I. $20-45$ & $53(29.0)$ & $34(16.3)$ & $46(20.1)$ \\
\hline 2. $46-65$ & $96(52.4)$ & $95(45.7)$ & $116(50.6)$ \\
\hline 3. $\geq 66$ & $34(18.6)$ & $79(38.0)$ & $67(29.3)$ \\
\hline
\end{tabular}

Pearson chi-square: $P<0.00$ I, Spearman's $\rho=0.098(P=0.015)$

Duration of the illness (years)
I. $0.2-5$
$79(43.2) \quad 66(31.7) \quad 86(37.6)$
2. $5.1-10$
$63(34.4) \quad 60(28.9) \quad 69(30.1)$
3. $>10$
$41(22.4) \quad 82(39.4) \quad 74(32.3)$

Pearson chi-square: $P=0.010$, Spearman's $\rho=0.064(P=0.1$ I 3$)$

Relationship status

$\begin{array}{llll}\text { I. In a relationship } & 84(64.1 \%) & 119(61.3 \%) & 123(63.7 \%)\end{array}$

2. Living alone $\quad 47(35.9 \%) \quad 75(38.7 \%) \quad 70(36.3 \%)$

Pearson chi-square: $P=0.842$, Spearman's $\rho=-0.00$ I $(P=0.977)$

Education

$\begin{array}{llll}\text { I. Primary } & 68(37 . I) & 71(34.1) & 48(21.0) \\ \text { 2. High school } & 79(43.2) & 76(36.5) & 118(5 I .5) \\ \text { 3. College/university } & 36(19.7) & 6 I(29.3) & 63(27.5)\end{array}$

Pearson chi-square: $P<0.00$ I, Spearman's $\rho=0.132(P=0.00$ I)

Professional activity

$\begin{array}{llll}\text { I. Active } & 95(51.9) & 93(44.7) & 98(42.8) \\ \text { 2. Not active } & 88(48.1) & 1 \mid 5(55.3) & 131(57.2)\end{array}$

Pearson chi-square: $P=0.161$, Spearman's $\rho=0.072(P=0.074)$

ESC hypertension grade

I. 120-129 and/or 80-84 $20(10.9) \quad 15(7.2) \quad 35(15.3)$

2. $130-139$ and/or $85-89 \quad 36(19.7) \quad 43(20.7) \quad 52(22.7)$

3. $140-159$ and/or $90-99 \quad 98(53.6) \quad 93(44.7) \quad 96(41.9)$

4. $160-169$ and/or 100-109 29 (15.8) $57(27.4) \quad 46(20.1)$

Pearson chi-square: $P=0.012$, Spearman's $\rho=-0.037(P=0.057)$

Way of taking medication

I. Directly from the blister 23 (I2.6) 27 (13.0) 26 (II.4)

2. From a dispenser box $\quad 20(10.9) \quad 37(17.8) \quad 4 I(17.9)$

3. Administered by a caregiver $\quad 140(76.5) \quad 144(69.2) \quad 162(70.7)$

Pearson chi-square: $P=0.292$, Spearman's $\rho=-0.038(P=0.347)$

Hypertension treatment

I. Monotherapy $\quad 18(9.8) \quad 13(6.2) \quad 7(3.1)$

2. Polytherapy $\quad 115(62.8) \quad 117(56.3) \quad 116(50.6)$

3. Polytherapy in one tablet $50(27.3) \quad 78(37.5) \quad 106(46.3)$

Pearson chi-square: $P<0.00$ I, Spearman's $\rho=0.176(P<0.00$ I)

AIS level

$\begin{array}{llll}\text { I. Low } & 20(10.9) & 17(8.2) & 19(8.3) \\ \text { 2. Medium } & 80(43.7) & 100(48.1) & 82(35.8) \\ \text { 3. High } & 83(45.4) & 91(43.7) & 128(55.9)\end{array}$

Pearson chi-square: $P=0.062$, Spearman's $\rho=0.090(P=0.024)$

Notes: Use of the OMMAS is protected by US and International copyright laws. The permission for use is required. A license agreement is available from Donald E Morisky, MMAS Research (MORISKY) 16636 159th Place SE, Renton, WA 98058 USA, dmorisky@gmail.com.

Abbreviations: AIS, Acceptance of Illness Scale; ESC, European Society of Cardiology; MMAS-8, 8-item Morisky Medication Adherence Scale. 
the HT, the type of the pharmacological treatment, and the illness acceptance $(P<0.05)$ (Table 3$)$. For these variables, the OR was calculated.

The results of OR showed that the chance for high adherence in women was 1.5 times lower than in men ( 32.4 vs $40.8 \%$ ). The chance for high adherence in patients aged $>65$ years was lower than in patients aged $>45$ years (OR $=0.70)$, but the impact of age was not statistically significant $(\mathrm{OR}=0.61-2.08)$. The chance for high adherence in patients with secondary education was over twice higher than in patients with primary education ( $O R=2.20)$ and $>1.5$ times higher than in patients with university education $(\mathrm{OR}=1.88)$.

The chance for high adherence in patients with HT of stages 3 and 4 according to ESC was $>1.5$ times lower than in patients with HT of stage $1(\mathrm{OR}=0.50$ and 0.53$)$. The chance for high adherence in patients with monotherapy

Table 4 OR for the significant variable in comparative analysis of the adherence level with the selected sociodemographic and clinical determinants

\begin{tabular}{|c|c|c|c|}
\hline \multirow[t]{2}{*}{ Variable } & \multicolumn{2}{|c|}{$\begin{array}{l}\text { Adherence level, } \\
\text { n (\%) }\end{array}$} & \multirow[t]{2}{*}{ OR $(95 \% \mathrm{Cl})$} \\
\hline & High & $\begin{array}{l}\text { Low to } \\
\text { moderate }\end{array}$ & \\
\hline \multicolumn{4}{|l|}{ Sex } \\
\hline Male & $136(40.8)$ & $197(59.2)$ & $\mathrm{I} .00$ (ref) \\
\hline Female & $93(32.4)$ & $194(67.6)$ & $0.69(0.50-0.97)$ \\
\hline \multicolumn{4}{|l|}{ Age (years) } \\
\hline $20-45$ & $37(66.1)$ & $19(33.9)$ & $\mathrm{I} .00$ (ref) \\
\hline $46-65$ & $180(68.7)$ & $82(31.3)$ & $\mathrm{I} .13(0.6 \mathrm{I}-2.08)$ \\
\hline$\geq 66$ & $174(57.6)$ & $128(42.4)$ & $0.70(0.38-1.27)$ \\
\hline \multicolumn{4}{|l|}{ Education } \\
\hline Primary & $48(25.7)$ & $139(74.3)$ & $\mathrm{I} .00$ (ref) \\
\hline High school & $118(43.2)$ & $155(56.8)$ & $2.20(\mid .47-3.31)$ \\
\hline College/university & $63(39.4)$ & $97(60.6)$ & $1.88(1.19-2.97)$ \\
\hline \multicolumn{4}{|l|}{ ESC hypertension grade } \\
\hline $120-129$ and/or $80-84$ & $35(50.0)$ & $35(50.0)$ & 1.00 (ref) \\
\hline |30-139 and/or 85-89 & $52(39.7)$ & $79(60.3)$ & $0.66(0.37-I .18)$ \\
\hline |40-159 and/or 90-99 & $96(33.4)$ & $191(66.6)$ & $0.50(0.30-0.85)$ \\
\hline $160-169$ and/or 100-109 & $46(34.8)$ & $86(65.2)$ & $0.53(0.30-0.96)$ \\
\hline \multicolumn{4}{|l|}{ Duration of the illness (years) } \\
\hline $0.2-5$ & $145(74.9)$ & $222(60.3)$ & $\mathrm{I} .00$ (ref) \\
\hline $5.1-10$ & $123(63.3)$ & $55(59.8)$ & $1.02(0.64-1.63)$ \\
\hline$>10$ & $123(6 \mid .8)$ & II 4 (7I.3) & $1.93(1.07-2.92)$ \\
\hline \multicolumn{4}{|l|}{ Hypertension treatment } \\
\hline Polytherapy & $7(18.4)$ & $31(81.6)$ & $\mathrm{I} .00$ (ref) \\
\hline Monotherapy & $116(33.3)$ & $232(66.7)$ & $0.60(0.43-0.85)$ \\
\hline Polytherapy in one tablet & $106(45.3)$ & $128(54.7)$ & $0.27(0.12-0.64)$ \\
\hline \multicolumn{4}{|l|}{ IIlness acceptance } \\
\hline Low $(\mathrm{N}=56)$ & $19(33.9)$ & $37(66.1)$ & $\mathrm{I} .00$ (ref) \\
\hline Medium $(\mathrm{N}=262)$ & $82(31.3)$ & $180(68.7)$ & $0.89(0.48-1.64)$ \\
\hline High $(\mathrm{N}=302)$ & $128(42.4)$ & $174(57.6)$ & $\mathrm{I} .43(0.78-2.6 \mathrm{I})$ \\
\hline
\end{tabular}

Abbreviations: ESC, European Society of Cardiology; OR, odds ratio; ref, reference. was $>1.5$ times lower than in patients with polytherapy in one tablet $(\mathrm{OR}=0.60)$ and even much lower in patients with polytherapy $(\mathrm{OR}=0.27)$. The chance for high adherence in patients with high illness acceptance was higher than in patients with low illness acceptance $(\mathrm{OR}=1.43)$. However, the $95 \%$ CI for OR contained value 1, which meant that the impact of high illness acceptance on high adherence was not statistically significant (Table 4).

The Mantel-Haenszel OR adjusted for sex, age, illness duration, marital status, professional activity, and polytherapy in one tablet is $\mathrm{OR}_{\mathrm{MH}}=1.63$ with a $95 \% \mathrm{CI}$ of 1.50-1.77. Patients with a high acceptance of illness are $>1.5$ times more likely to show high adherence than those with a low illness acceptance level. The adjusted $\mathrm{OR}_{\mathrm{MH}}$ has a much narrower CI than OR values in other patient subgroups (Figure 1) and is further from $\mathrm{OR}=1$, which indicates that the analyzed socioclinical characteristics are confounding variables, affecting the correlation between adherence and acceptance. Adjusting for these variables resulted in a narrower $\mathrm{CI}$ for the $\mathrm{OR}$.

In summary, a significant correlation can be seen between acceptance of illness and adherence to pharmacological treatment, though some socioclinical characteristics are equally significant, both for acceptance of illness and for adherence to pharmacological treatment in HT.

\section{Discussion}

The understanding of determinants of adherence to pharmacological treatment in HT is key to treatment planning. Effective identification of patients at risk of pharmacological nonadherence might be especially helpful in planning interventions to enhance illness control, prevent complications, improve long-term treatment outcomes, and limit adverse outcomes in these patients. According to published studies, adherence mainly depends on the patients' knowledge and their sociodemographic characteristics, such as sex, age, education, and marital status. Psychosocial factors, which have not been extensively studied until recently, may also have a significant impact on chronic illness management. ${ }^{12-15}$ Researchers have pointed to several such factors, including social support, perception and acceptance of illness, cognitive impairment, and depression. ${ }^{16}$

The author's own study showed a statistically significant but weak correlation between acceptance of illness and adherence scores, especially in the group of male patients, aged $\geq 45-65$, diagnosed with HT at least 10 years before, marital status, professionally active, and receiving one-tablet polytherapy. Female sex, age $<66$ years, shorter duration of illness, higher stage of the HT (third grade ESC and fourth 


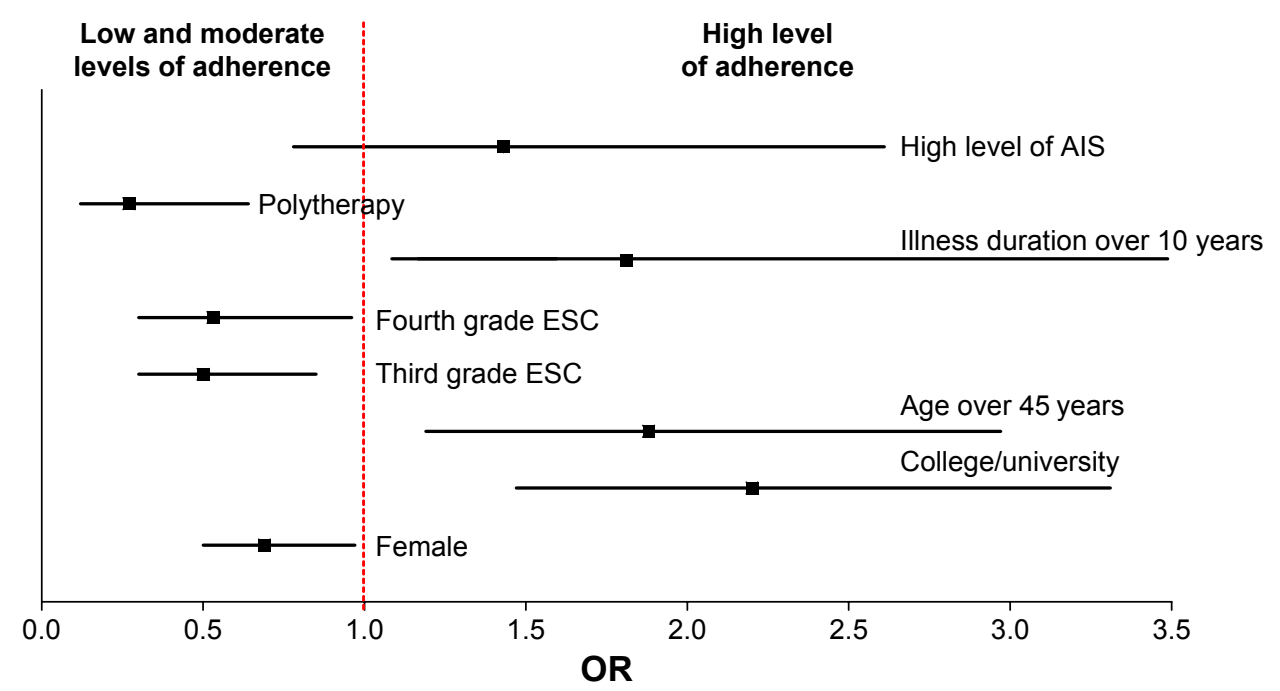

Figure I ORs and their $95 \%$ Cls.

Abbreviations: AIS, Acceptance of Illness Scale; ESC, European Society of Cardiology; ORs, Odds ratios.

grade ESC), and being treated with polytherapy were found to be confounding variables in terms of the correlation between adherence.

One interesting finding in our study is the lack of significant correlation between adherence to pharmacological treatment and acceptance of illness. In the comparative analysis, the patients with high level of the acceptance of the disease had higher level of adherence into recommendations in MMAs-8 questionnaire. But in the OR analysis, despite the fact that the patients with high illness acceptance got higher pharmacological adherence scores, the results were not statistically significant. The OR shows that high adherence to pharmacological treatment is $>1.5$ times as likely to occur in the high acceptance group as in the low-to-moderate acceptance group. Published studies prove that illness perception and attitude toward treatment play an important role in adherence to therapeutic instructions. ${ }^{15,24,25}$

Illness acceptance results in a sense of security and mitigates negative emotions related to the illness and treatment. Higher levels of illness acceptance are correlated with a reduction in negative reactions to the illness, which increases the patient's involvement in treatment. In previous studies, acceptance of illness was correlated with better adherence to treatment, ${ }^{16}$ but especially, significant correlations in singlefactor analysis were only found with regard to the patients' health-related behaviors.

In a study by Rajpura and Nayak, ${ }^{25}$ multiple-factor analysis showed that perception of illness and attitude toward treatment have a significant influence on adherence scores. ${ }^{25}$ Other researchers have identified self-efficacy and perception of illness as factors affecting adherence to pharmacological treatment. ${ }^{26,27}$

Poor adherence is found in patients who believe that HT medication has adverse effects. ${ }^{28}$ Moreover, improved knowledge of HT may affect patients' acceptance of illness and their beliefs related to the illness and its treatment. ${ }^{2,29}$ However, few studies ${ }^{25}$ exist to confirm the correlation between acceptance of illness and adherence to pharmaceutical treatment ${ }^{16}$ and the available articles mainly focus on AIS in the context of quality of life in chronic illness. ${ }^{30-32}$

The role of a patient's sex in adherence is often discussed, but so far, contradictory findings have been published. In the author's own study, male sex was found to be a determinant of adherence and illness acceptance. In the literature, contradictory reports can be found on the relationship between sex and adherence. In a study by Hyre et al, ${ }^{33}$ female patients had lower adherence scores, while in a study by Kim et al, ${ }^{34}$ lower adherence was found in black male patients.

Another determinant of higher adherence in the authors' study was age $>66$ years. Age $<66$ years was a confounder in the correlation of adherence to pharmacological treatment. This study can contribute to the discussion on the relationship between age and adherence. According to some reports, younger patients show better adherence to pharmacological treatment, ${ }^{5,35}$ while others state that young age is a determinant of poorer adherence to hypotensive medication. ${ }^{36,37}$ Some researchers have also found better adherence among elderly patients. ${ }^{25,38-40}$ Nonadherence in younger patients may be due to the lack of persistent symptoms at early stages of the illness or to concerns about medication side effects. The better adherence to treatment found in elderly patients 
has been explained by the presence of comorbidities, which make the patients perceive themselves as very ill and take the prescribed treatment seriously. ${ }^{37}$

In the own study, being in a relationship was not regarded as a significant factor increasing adherence. Notably, published articles confirm better adherence found in patients supported by family members and friends. ${ }^{33,41,42}$ Meinema et $\mathrm{al}^{29}$ showed that patients who adhere to treatment typically experience family support, while Maguire et $\mathrm{al}^{43}$ reported strong social support enjoyed by high-adherence patients. Patients who receive social support, maintain a healthy diet, and take their medication regularly are capable of recognizing the symptoms of illness exacerbation. ${ }^{44}$

Illness duration is another factor that may affect adherence. In this study, illness duration exceeding 10 years was correlated with higher adherence scores. Similarly, Hyre et $\mathrm{al}^{33}$ reported that a time from HT diagnosis of $<10$ years was correlated with lower adherence scores, but these results were not statistically significant. Lee reported a correlation between shorter duration of HT ( $<5$ years) and poorer adherence to pharmacological treatment. This may be explained by improved awareness and understanding of the illness in patients who have been treated for a longer time. The patients may be better informed on the importance of consistent treatment and the related limitations. ${ }^{33}$ They are more experienced, have established a better physician-patient relationship, and have greater faith in their physician's advice. In addition, they might become more knowledgeable about their own health and the appropriate disease management and control. ${ }^{45,46}$ In the literature, studies exist that corroborate our reports of a correlation between longer illness duration and higher adherence scores..$^{33,37}$

Another factor correlated with adherence to treatment is the type and quantity of medication. In this study, combined treatment administered in one tablet was positively correlated with adherence. Other researchers also report that patients show better adherence if they are prescribed one drug or a single daily dose. ${ }^{36,41}$ They also found a correlation between adherence and the number of drugs prescribed. Fewer drugs contributed to better adherence. ${ }^{32}$

\section{Study limitations}

One limitation is the fact that the level of adherence in our study was only measured using a direct method based on a self-reported questionnaire. The results were not verified by indirect methods, such as the use of physiological markers, pharmacy records, the measurement of drug concentration in body fluids, the activity of selected biochemical markers of tablets in serum, and drug concentrations in body fluids for monitoring the treatment. The risk of under-or overestimation in this method is connected with the individual variability in drug metabolism, especially in elderly people. The use of the electronic reader is expensive and does not consider the case of the opening of the box without taking the medicine. However, it is the most accurate method of the evaluation of the adherence. ${ }^{47}$

Another limitation could be the fact that patients' satisfaction with the treatment process and their knowledge on the illness were not assessed.

\section{Conclusion}

Findings from this study provide clear evidence to physicians and health care policymakers that there is no single factor that can be deemed solely responsible for influencing drug adherence among patients, as the problem of nonadherence is multifactorial.

Acceptance of illness is correlated with adherence to pharmacological treatment, and consideration should be given to more widespread assessment of illness acceptance in daily practice.

Male sex, higher education, lower stage of HT (according the grade ESC), and receiving one-tablet polytherapy are significant determinants of adherence to pharmacological treatment in HT.

\section{Implication for practice}

The problem of patients' poor adherence to therapeutic recommendations in long-term treatment requires special interventions. Daily medical practice should include continuous evaluation of illness acceptance and adherence to HT treatment, so that nonadhering patients can be given additional attention. Patients need information to understand the nature of their illness and the importance of adherence to treatment. Each visit should be accompanied by counseling to improve adherence to treatment, as well as to enhance acceptance and perception of the illness. Health care providers need to focus on patients' behaviors that may interfere with adherence to treatment in order to gain control of HT in the community. Health care professionals should identify the available (viable) strategies for increasing adherence in their daily practice.

\section{Abbreviations}

AIS, Acceptance of Illness Scale; BP, blood pressure; ESC, European Society of Cardiology; ESH, European Society of Hypertension; HBP, high blood pressure; HT, hypertension; 
M, median; MMAS-8, 8-item Morisky Medication Adherence Scale; OR, odds ratio; SD, standard deviation; WHO, World Health Organization.

\section{Acknowledgments}

The authors thank Professor Donald E Morisky for his assistance and for his permission to use CMorisky Medication Adherence Scale (MORISKY) (Use of the CMMAS is protected by US and International copyright laws. Permission for use is required. A license agreement is available from: Donald E Morisky, MMAS Research [MORISKY)] 16636 159th Place SE, Renton WA 98058,dmorisky@gmail.com). There was no external source of funding for this research. All coauthors have agreed to the submission and publication of this article.

\section{Author contributions}

$\mathrm{BJ}-\mathrm{P}, \mathrm{AC}, \mathrm{IU}, \mathrm{KD}$, and GM were responsible for the conception and design, acquisition of data, analysis and interpretation of data, drafting the initial manuscript, and revising it critically for important intellectual content. BJ-P wrote this article. All authors contributed toward data analysis, drafting and critically revising the paper and agree to be accountable for all aspects of the work. All authors read and approved the final article.

\section{Disclosure}

The authors report no conflicts of interest in this work.

\section{References}

1. Irvin MR, Shimbo D, Mann DM, et al. Prevalence and correlates of low medication adherence in apparent treatment-resistant hypertension. J Clin Hypertens (Greenwich). 2012;14(10):694-700.

2. Almas A, Godil SS, Lalani S, Samani ZA, Khan AH. Good knowledge about hypertension is linked to better control of hypertension; a multicentre cross sectional study in Karachi, Pakistan. BMC Res Notes. 2012;5:579.

3. Grahame-Smith DG, Aronson JK. Oxford Textbook of Clinical Pharmacology and Drug Therapy. 3rd ed. Oxford: Oxford University Press; 2002.

4. Carter S, Taylor D, Levenson R. A Question of Choice-Compliance in Medicine Taking. From Compliance to Concordance. 3rd ed. London: Medicines Partnership; 2005.

5. Jackevicius CA, Mamdani M, Tu JV. Adherence with statin therapy in elderly patients with and without acute coronary syndromes. JAMA. 2002;288(4):462-467.

6. Cramer J, Rosenheck R, Kirk G, Krol W, Krystal J; VA Naltrexone Study Group 425. Medication compliance feedback and monitoring in a clinical trial: predictors and outcomes. Value Health. 2003;6(5):566-573.

7. Wolf-Maier K, Cooper RS, Kramer H, et al. Hypertension treatment and control in five European countries, Canada, and the United States. Hypertension. 2004;43(1):10-17.

8. He W, Bonner A, Anderson D. Patient reported adherence to hypertension treatment: a revalidation study. Eur J Cardiovasc Nurs. 2016;15(2): $150-156$.
9. DiMatteo MR, Giordani PJ, Lepper HS, Croghan TW. Patient adherence and medical treatment outcomes: a meta-analysis. Med Care. 2002;40: 794-811.

10. AlGhurair SA, Hughes CA, Simpson SH, Guirguis LM. A systematic review of patient self-reported barriers of adherence to antihypertensive medications using the world health organization multidimensional adherence model. J Clin Hypertens (Greenwich). 2012;14(12): 877-886.

11. Sabaté E, editor. Adherence to Long-Term Therapies: Evidence for Action. World Health Organization, Geneva, Switzerland; 2003.

12. Sabate $\mathrm{E}$ [webpage on the Internet]. Adherence to long-term therapies. Evidence for action; 2003. Geneva, Switzerland: World Health Organization. Available from: http://www.who.int/chp/knowledge/publications/adherence_report/en/index.html. Accessed February 3, 2016.

13. Monane M, Bohn RL, Gurwitz JH, et al. The effects of initial drug choice and comorbidity on antihypertensive therapy compliance: results from a population - based study in the elderly. Am J Hypertens. 1997;10:697-704.

14. Morris AB, Li J, Kroenke K, Bruner-England TE, Young JM, Murray MD. Factors associated with drug adherence and blood pressure control in patients with hypertension. Pharmacotherapy. 2006;26(4):483-492.

15. Chen SL, Tsai JC, Chou KR. Illness perceptions and adherence to therapeutic regimens among patients with hypertension: a structural modeling approach. Int J Nurs Stud. 2011;48(2):235-245.

16. Jankowska-Polańska B, Blicharska K, Uchmanowicz I, Morisky DE. The influence of illness acceptance on the adherence to pharmacological and non-pharmacological therapy in patients with hypertension. Eur $J$ Cardiovasc Nurs. 2016;15(7):559-568.

17. Weinert CL. Evolution of a conceptual model for adaptation to chronic illness. J Nurs Scholarsh. 2008;40(4):364-372.

18. Chan R, Brooks R, Steel Z, et al. The psychosocial correlates of quality of life in the dialysis population: a systematic review and metaregression analysis. Qual Life Res. 2012;21(4):563-580.

19. Hosseininasab M, Jahangard-Rafsanjani Z, Mohagheghi A, et al. Self-monitoring of blood pressure for improving adherence to antihypertensive medicines and blood pressure control: a randomized controlled trial. Am J Hypertens. 2014;27(11):1339-1345.

20. Gohar F, Greenfield SM, Beevers DG, Lip GY, Jolly K. Self-care and adherence to medication: a survey in the hypertension outpatient clinic. BMC Complement Altern Med. 2008;8:4.

21. $2013 \mathrm{ESH} / \mathrm{ESC}$ Guidelines for the management of arterial hypertension. The Task Force for the management of arterial hypertension of the European Society of Hypertension (ESH) and of the European Society of Cardiology (ESC). Eur Heart J. 2013;34:2159-2219.

22. Juczyński Z. Measurement Instruments in the Promotion and Psychology of Health. Warsaw: Psychological Test Workshop, Polish Psychological Society; 2001:110-115;162-167.

23. Morisky DE, Ang A, Krousel-Wood M, Ward HJ. Predictive validity of a medication adherence measure in an outpatient setting. J Clin Hypertens. 2008;10(5):348-354.

24. Chen SL, Tsai JC, Lee WL. The impact of illness perception on adherence to therapeutic regimens of patients with hypertension in Taiwan. J Clin Nurs. 2009;18(15):2234-2244.

25. Rajpura J, Nayak R. Medication adherence in a sample of elderly suffering from hypertension: evaluating the influence of illness perceptions, treatment beliefs, and illness burden. J Manag Care Pharm. 2014;20(1):58-65.

26. Schoenthaler AM, Butler M, Chaplin W, Tobin J, Ogedegbe G. Predictors of changes in medication adherence in blacks with hypertension: moving beyond cross-sectional data. Ann Behav Med. 2016;50(5):642-652.

27. Mollaoğlu M, Solmaz G, Mollaoğlu M. Adherence to therapy and quality of life in hypertensive patients. Acta Clin Croat. 2015;54(4): 438-444.

28. Fernandez-Arias M, Acuna-Villaorduna A, Miranda JJ, Diez-Canseco F, Malaga G. Adherence to pharmacotherapy and medication-related beliefs in patients with hypertension in Lima, Peru. PLoS One. 2014;9(12):e112875. 
29. Meinema JG, van Dijk N, Beune EJ, Jaarsma DA, van Weert HC, Haafkens JA. Determinants of adherence to treatment in hypertensive patients of African descent and the role of culturally appropriate education. PLoS One. 2015;10(8):e0133560.

30. Obiegło M, Uchmanowicz I, Wleklik M, Jankowska-Polańska B, Kuśmierz M. The effect of acceptance of illness on the quality of life in patients with chronic heart failure. Eur J Cardiovasc Nurs. 2016;15(4): 241-247.

31. Jankowska-Polańska B, Kasprzyk M, Chudiak A, Uchmanowicz I. Effect of disease acceptance on quality of life in patients with chronic obstructive pulmonary disease (COPD). Pneumonol Alergol Pol. 2016; 84(1):3-10.

32. Mroczek B, Sitko Z, Augustyniuk K, Pierzak-Sominka J, Wróblewska I, Kurpas D. Socioeconomic indicators shaping quality of life and illness acceptance in patients with chronic obstructive pulmonary disease. $A d v$ Exp Med Biol. 2015;861:19-30.

33. Hyre AD, Krousel-Wood MA, Muntner P, Kawasaki L, DeSalvo KB. Prevalence and predictors of poor antihypertensive medication adherence in an urban health clinic setting. J Clin Hypertens (Greenwich). 2007;9(3):179-186.

34. Kim MT, Han HR, Hill MN, Rose L, Roary M. Depression, substance use, adherence behaviors, and blood pressure in urban hypertensive black men. Ann Behav Med. 2003;26(1):24-31.

35. Lam PW, Lum CM, Leung MF. Drug non-adherence and associated risk factors among Chinese geriatric patients in Hong Kong. Hong Kong Med J. 2007;13(4):284-292.

36. Kamran A, Sadeghieh Ahari S, Biria M, Malepour A, Heydari H. Determinants of patient's adherence to hypertension medications: application of health belief model among rural patients. Ann Med Health Sci Res 2014;4(6):922-927.

37. Lee GK, Wang HH, Liu KQ, Cheung Y, Morisky DE, Wong MC. Determinants of medication adherence to antihypertensive medications among a Chinese population using Morisky Medication Adherence Scale. PLoS One. 2013;8(4):e62775.
38. Burnier M. Medication adherence and persistence as the cornerstone of effective antihypertensive therapy. Am J Hypertens. 2006;19(11): 1190-1196.

39. Krousel-Wood MA, Islam T, Webber LS, Re RS, Morisky DE, Muntner P. New Medication Adherence Scale versus pharmacy fill rates in seniors with hypertension. Am J Manag Care. 2009;15(1):59-66.

40. Carter BL, Foppe van Mil JW. Comparative effectiveness research: evaluating pharmacist interventions and strategies to improve medication adherence. Am J Hypertens. 2010;23(9):949-955.

41. Dunbar BS, Clark CP, Quinn C, et al. Family influences on heart failure self - care and outcomes. J Cardiovasc Nurs. 2008;23:258-265.

42. Wang PS, Bohn RL, Knight E, Glynn RJ, Mogun H, Avorn J. Noncompliance with antihypertensive medications: the impact of depressive symptoms and psychosocial factors. J Gen Intern Med. 2002;17(7): 504-511.

43. Maguire LK, Hughes CM, McElnay JC. Exploring the impact of depressive symptoms and medication beliefs on medication adherence in hypertension - a primary care study. Patient Educ Couns. 2008; 73(2):371-376.

44. Scheurer D, Choudhry N, Swanton KA, et al. Association between different types of social support and medication adherence. Am J Manag Care. 2012;18:e461-e467.

45. Svensson S, Kjellgren KI, Ahlner J, Saljo R. Reasons for adherence with antihypertensive medication. Int J Cardiol. 2000;76:157-163.

46. Morisky DE, DiMatteo MR. Improving the measurement of selfreported medication nonadherence: final response. $J$ Clin Epidem. 2011;64:258-263.

47. Eskås PA, Heimark S, Mariampillai JE, et al. Medication adherence and monitoring of antihypertensive treatment. Tidsskr Nor Laegeforen. 2016;136(10):920-923.
Patient Preference and Adherence

\section{Publish your work in this journal}

Patient Preference and Adherence is an international, peer-reviewed, open access journal that focuses on the growing importance of patient preference and adherence throughout the therapeutic continuum. Patient satisfaction, acceptability, quality of life, compliance, persistence and their role in developing new therapeutic modalities and compounds to optimize

\section{Dovepress}

clinical outcomes for existing disease states are major areas of interest for the journal. This journal has been accepted for indexing on PubMed Central. The manuscript management system is completely online and includes a very quick and fair peer-review system, which is all easy to use. Visit http://www. dovepress.com/testimonials.php to read real quotes from published authors. 